\title{
Ecoturismo: a conservação da natureza como alternativa aos Grandes Projetos de Investimento (GPIs) no Rio de Janeiro
}

\author{
Ecotourism: Nature Conservation as an Alternative to \\ Large Investment Projects (LIPs) in Rio de Janeiro State, Brazil
}

Rodrigo Machado Vilani

RESUMO: O presente artigo tem como objetivo discutir e produzir apontamentos sobre o uso das Unidades de Conservação, federais e estaduais, localizadas no Rio de Janeiro, como unidades territoriais de planejamento governamental, relevando o ecoturismo como alternativa ao padrão primário-exportador de desenvolvimento, pautado em grandes projetos de investimento. Esse padrão degrada os biomas brasileiros, fragmenta o território e acentua desigualdades sociais e regionais. Estudos sobre o ecoturismo têm o papel de contribuir para a consolidação de uma alternativa a esse padrão de desenvolvimento. Para tanto, metodologicamente, optou-se por uma pesquisa exploratória-descritiva e por uma abordagem interdisciplinar, integrando conhecimentos, conceitos e métodos aplicados ao recorte proposto, com ênfase nas contribuições das áreas do Turismo, das Ciências Ambientais e do Planejamento Regional. Foram tecidas considerações gerais e específicas quanto aos desafios e às possibilidades de consolidação do ecoturismo como a atividade central para se avançar em um padrão de desenvolvimento integrado, participativo e de longo prazo.

PALAVRAS-CHAVE: Ecoturismo; Desenvolvimento; Rio de Janeiro; Grandes Projetos de Investimento; Conservação.

\begin{abstract}
The objective of this paper is to discuss and produce notes on the use of federal and state Protect Areas located in Rio de Janeiro as territorial units for governmental planning, highlighting ecotourism as an alternative to the primary exporting pattern of development, based on large investment projects. This pattern degrades the Brazilian biomes, fragments the territory and accentuates social and regional inequalities. Studies on ecotourism have the role of contributing to the consolidation of an alternative to this pattern of development. For that, methodologically, an exploratorydescriptive research and a interdisciplinary approach were chosen, integrating knowledge, concepts and methods applied to the proposed cut, with emphasis on the contributions of the areas of Tourism, Environmental Sciences and Regional Planning. General and specific considerations regarding the challenges and possibilities for the consolidation of ecotourism as a central activity were developed to advance an integrated, participatory and long-term development pattern.
\end{abstract}

KEYWORDS: Ecotourism; Development; Rio de Janeiro; Major Investment Projects; Conservation. 


\section{Introdução}

Em 2016, acentuou-se uma crise institucional no Brasil e, de forma ainda mais grave, no Estado do Rio de Janeiro. A queda do preço internacional de commodities, especialmente do petróleo, acentuou a crise econômica e contribuiu para um processo político conflituoso que persiste nas esferas federal e estadual. A conjuntura nacional é extremamente complexa e paradoxal, condizente com a prática do presidencialismo de coalização, adotado no País (MACHADO; VILANI, 2015, 2016). Apesar da situação atual, persiste uma propaganda oficial de progresso alcançado por meio de avanços nas áreas de energia, agricultura, mineração e, em particular, com os grandes projetos de investimento (GPIs) retomados com os Programas de Aceleração do Crescimento (PACs 1 e 2) lançados em 2007 e 2010. Entre os principais projetos dos PACs 1 e 2 estão: a Ferrovia Norte-Sul, as Usinas Hidrelétricas Belo Monte (PA), Jirau (RO) e Santo Antônio (RO), a Usina Termelétrica Nuclear Angra 3 (RJ), o Complexo Petroquímico do Rio de Janeiro (RJ), a Refinaria Abreu e Lima (PE) e o Campo de Papa Terra - Módulos 1 e 2 (RJ). De maneira geral, o processo decisório para implantação e execução desses empreendimentos foi conduzido a par da avaliação técnica de órgãos ambientais e impediu uma efetiva participação da sociedade e destruíram processos ecológicos essenciais em diferentes biomas brasileiros, notadamente na Amazônia e na Mata Atlântica. Daí a crescente judicialização e perda de eficiência do licenciamento ambiental no Brasil, das quais Belo Monte e a Barragem de Fundão, em Mariana/MG, atualmente são os principais exemplos de violação de direitos ambientais, sociais e culturais.

O avanço de barragens, pastagens, madeireiras, plantações, rodovias, portos, aeroportos e ferrovias, historicamente, desencadeou o desmatamento e a fragmentação dos biomas brasileiros. Em escala nacional, Vainer (2007) critica os GPIs como vetores de fragmentação territorial. Segundo o autor "[d]esde a metade do século passado, mas sobretudo a partir de seu último quartel, grandes projetos minero-metalúrgicos, petroquímicos, energéticos e viários reconfiguraram o território nacional" (VAINER, 2007, p.11). Atualmente, o aporte do capital privado, contrariamente ao controle estatal dos anos 1970, produziu uma responsabilidade pela infraestrutura que "acabou tendo como corolário a privatização dos processos de planejamento e controle territorial que são intrínsecos aos grandes projetos" (VAINER, 2007, p.11).

Essa privatização pode ser exemplificada a partir de uma leitura que se inicia com a área referente à porção continental do Brasil $-8.514 .085 \mathrm{~km}^{2}$. Deste total, $523.440 \mathrm{~km}^{2}$ são cobertos por unidades de conservação de proteção integral, isto é, $6,1 \%$ do território nacional. As unidades de uso sustentável somam $974.791 \mathrm{~km}^{2}, 11 \%$ de toda porção continental do País. Portanto, o Brasil conta com um total de $17 \%$ de áreas protegidas, acima da média mundial - de 2014 - que foi de "15,4\% para as áreas terrestres excluída a Antártica e 8,4\% para as áreas marinhas com jurisdição nacional" (TCU, 2014, p. 8). Esses dados, do Cadastro Nacional de Unidades de Conservação do Ministério do Meio Ambiente (MMA) (BRASIL, 2016), encontram-se, também, detalhados por bioma brasileiro (Quadro 1). 
Quadro 1: Unidades de Conservação por bioma na porção continental do Brasil.

Table 1: Protect Areas per biome in the continental portion of Brazil

\begin{tabular}{|l|c|c|c|c|c|c|}
\hline \multicolumn{1}{|c|}{ Bioma } & Amazônia & Caatinga & Cerrado & $\begin{array}{c}\text { Mata } \\
\text { Atlântica }\end{array}$ & Pampa & Pantanal \\
\hline Área total & $\mathbf{4 . 1 9 8 . 5 5 1}$ & $\mathbf{8 2 7 . 9 3 4}$ & $\mathbf{2 . 0 4 0 . 1 6 7}$ & $\mathbf{1 . 1 1 7 . 5 7 1}$ & $\mathbf{1 7 8 . 7 0 4}$ & $\mathbf{1 5 1 . 1 5 9}$ \\
\hline GPI & 417.493 & 9.893 & 62.813 & 28.210 & 628 & 4.403 \\
\hline GUS & 719.706 & 53.593 & 111.190 & 83.582 & 4.232 & 2.488 \\
\hline $\begin{array}{l}\text { GPI+GUS } \\
\text { (\%/bioma) }\end{array}$ & $27,1 \%$ & $7,7 \%$ & $8,5 \%$ & $10,0 \%$ & $2,7 \%$ & $4,6 \%$ \\
\hline $\begin{array}{l}\text { GPI+GUS } \\
\text { (\%/nacional) }\end{array}$ & $13,4 \%$ & $0,7 \%$ & $2,0 \%$ & $1,3 \%$ & $0,1 \%$ & $0,1 \%$ \\
\hline
\end{tabular}

Fonte: Elaborado a partir de Brasil (2016). Source: Elaborated from: Brazil (2016).

GPI: grupo de proteção integral;

GUS: grupo de uso sustentável;

GPI+GUS (\%/bioma): razão entre a área das unidades de conservação do bioma e a área total do bioma;

GPI+GUS (\%/nacional): razão entre a área das unidades de conservação do bioma e a área continental total.

O Quadro 1 privilegiou os biomas continentais, uma vez que, na área marinha correspondente ao Mar Territorial e à Zona Econômica Exclusiva, apenas $1,5 \%$, isto é, $54.538 \mathrm{Km}^{2}$ (GPI+GUS) de um total de $3.333 .796 \mathrm{Km}^{2}$ encontram-se protegidos por unidades de conservação (BRASIL, 2016), ou seja, muito abaixo da média mundial, de 8,4\%. Dessa forma, a partir da leitura empregada, toda essa porção do território nacional está negligenciada por ações governamentais de conservação da natureza. Dos biomas continentais, portanto, Amazônia apresenta os melhores índices de proteção tanto em relação à área do bioma como ao total nacional. Na GPI+GUS (\%/bioma), Mata Atlântica está em segundo lugar com percentual bem abaixo do bioma amazônico e próximo de Cerrado e Caatinga. Logo, no Brasil, a área protegida de todos os biomas está abaixo da média mundial de 2014 , quando a cobertura de áreas protegidas esteve em "15,4\% para as áreas terrestres excluída a Antártica e 8,4\% para as áreas marinhas com jurisdição nacional" (TCU, 2014, p. 8).

Quando inexiste um esforço programático para conservação do patrimônio genético de todos os biomas nacionais, não há que se falar em eficácia dos comandos constitucionais previstos no art. 225. Esse alerta segue entendimento de Trajano (2010), que afirma que "no campo da conservação, falar em preservação da biodiversidade equivale a falar em preservação da variedade em todos os seus níveis de universalidade, incluindo suas causas e todas suas manifestações e componentes, da variação genética entre indivíduos à variação entre ecossistemas" (p. 136). Especificamente em relação à situação de Parques Estaduais no Rio de Janeiro, Vallejo (2005) considera baixos os investimentos em conservação ambiental e aponta três fatores que justificariam essa condição: i) priorização de atividades produtivas, com retorno de curto prazo; ii) concentração de investimentos na região metropolitana; e iii) divulgação insuficiente dos serviços ambientais oferecidos pelas UCs, acarretando baixo apelo social ao tema. 
A fragmentação de habitat é um dos principais resultados do isolamento da questão ambiental na agenda pública e representa uma ameaça central à proteção da biodiversidade (TABARELLI; GASCON, 2005). Esta consequência das ações humanas acentua-se quando relacionado ao habitat de espécies-chave como a onça-pintada. A redução da área de Mata Atlântica, devido à expansão urbana, à implantação de GPIs, à construção de rodovias (MACHADO, AVENA, 2003) e à existência de propriedades particulares em áreas rurais, deixou a onça-pintada praticamente extinta ao longo da extensão territorial desse bioma no País (LEITE, 2000), estando sua presença limitada a unidades de conservação (BRASIL, 2010, p. 3). Apesar de ser originalmente encontrada em todos os biomas brasileiros, exceto os Campos Sulinos, atualmente, as maiores extensões de sua ocorrência encontram-se na Amazônia e no Pantanal (BRASIL, 2010).

Trajano (2010, p.139), ao analisar as propostas de áreas prioritárias contidas na Portaria 126/2004, do Ministério do Meio Ambiente, especificamente no tocante aos seus objetivos ${ }^{1}$, estabelecidos no art. $1^{\circ}$, alerta para 0

(...) descompromisso com essa diretriz nacional da conservação, oficializada em Portaria em vigor, são os vários empreendimentos não sustentáveis, recentemente aprovados por instâncias governamentais do Estado de São Paulo, localizados em áreas de prioridade alta, muito alta e extremamente alta, como a região da Serra do Mar e litoral do Estado de São Paulo, onde especulação imobiliária e empreendimentos portuários, entre outros, exercem fortíssima pressão para mudanças na legislação ambiental.

No Estado do Rio de Janeiro, um dos poucos e principais redutos do que resta da biodiversidade da Mata Atlântica, esse modelo se reproduziu de maneira semelhante, de acordo com as especificidades relacionadas, basicamente, ao determinismo físico das jazidas petrolíferas. Investimentos em empreendimentos portuários, como a construção do Porto do Açu e a ampliação do Porto de Itaguaí, da cadeia petrolífera e petroquímica Complexo Petroquímico do Rio de Janeiro (COMPERJ), de infraestrutura, como o Arco Metropolitano do Rio de Janeiro, e na indústria de transformação, como as Siderúrgidas da Gerdau e da Temium, levaram o padrão de desenvolvimento, praticado na esfera federal, a praticamente toda extensão litorânea do Rio de Janeiro.

Cumpre destacar a sociodiversidade do Estado do Rio de Janeiro. Povos indígenas e comunidades tradicionais diversas que vivem e mantém seus usos, práticas e manifestações culturais em meio à Mata Atlântica. Existem sete terras indígenas, localizadas em áreas litorâneas de Mata Atlântica, ocupadas por cerca de 600 índios, dos quais os Guarani representam 94\%, aproximadamente 570 índios, tomando por base dados de 2010 (CPISP, 2018). No Estado, são 32 comunidades quilombolas certificadas pela Fundação Cultural Palmares (SEPPIR, 2018). Comunidades rurais, pescadores artesanais, marisqueiros, caiçaras, entre outros, compõem a riqueza cultural associada à natureza no Estado do Rio de Janeiro. A título 
de exemplo, a cultura caiçara tem sido pesquisada e são apresentados, na literatura, resultados relevantes sobre seu conhecimento de manejo da Mata Atlântica, uso de plantas medicinais e pesca (DIEGUES, 1999; ADAMS, 2000; BORGES; PEIXOTO, 2009; BRITO, SENNA-VALLE, 2011). Diegues (2008) destaca o etnoconhecimento caiçara em relação à fauna e enfatizando 0 respeito, em suas práticas de caça e pesca, aos seus ciclos de reprodução aves, peixes e mamíferos. O autor aponta também que em territórios caiçaras é possível observar melhor conservação da Mata Atlântica quando comparado com áreas exploradas pela agricultural industrial (DIEGUES, 2008).

O Estado do Rio de Janeiro, portanto, concentra relevante sociobiodiversidade, que representa a base material para a reprodução do ecoturismo. Além disso,

\begin{abstract}
O potencial de mercado do ecoturismo no Brasil é enorme e promissor. Resta saber se teremos capacidade de aproveitálo não só como um valioso instrumento de proteção do patrimônio ambiental e cultural, mas também como uma oportunidade de promoção de ascensão social e distribuição de renda. (LAYRARGUES, 2004, p. 4).
\end{abstract}

Diante desse contexto, o presente artigo tem como objetivo discutir e produzir apontamentos sobre o uso das unidades de conservação, federais e estaduais, localizadas no Rio de Janeiro, como unidades territoriais de planejamento governamental, relevando o ecoturismo como alternativa ao padrão primário-exportador de desenvolvimento, pautado em grandes projetos de investimento.

Uma vez que a discussão acerca do planejamento territorial a partir do ecoturismo em unidades de conservação é tema pouco explorado, optou-se por uma pesquisa exploratória-descritiva. A pesquisa terá uma abordagem interdisciplinar, integrando conhecimentos, conceitos e métodos aplicados ao recorte proposto, com ênfase nas contribuições das áreas do Turismo, das Ciências Ambientais e do Planejamento Regional. A opção metodológica é por uma pesquisa de cunho qualitativo com base em pesquisa bibliográfica, documental e levantamento de estatísticas oficiais.

\title{
Ecoturismo: perspectiva teórica e aplicabilidade
}

Não há uma definição consensual para o ecoturismo (PIRES, 1998; 2000; SONAGLIO; LAPOLLI, 2003). Pires (1998) aponta que a concepção de ecoturismo irá variar de acordo com os sujeitos do desenvolvimento do ecoturismo. Estes sujeitos, segundo o autor, estão organizados em cinco setores:

\footnotetext{
- o trade turístico, ou seja, operadores, agências, promotores,
} empresas de viagens, hotelaria, guias, etc.; 
- a área governamental e os organismos oficiais ligados ao turismo;

- as organizações não governamentais da área ambiental e conservacionista;

- as populações residentes nos destinos potenciais;

- o público turista e suas diferentes motivações de viagem;

- o meio acadêmico debruçado sobre a pesquisa e a reflexão do tema. (PIRES, 1998, p. 76).

De forma semelhante, Endres (1998, p. 44) compreende o ecoturismo como uma atividade, na qual há preponderância do setor privado, com diferentes portes de empreendimentos no trade turístico, e a finalidade de "atender a uma demanda específica de turistas moldados pelas novas exigências ecológicas de um mundo em transformação".

Diferentemente da perspectiva estritamente mercadológica, Wearing e Neil (2001) definem o ecoturismo como "um veículo para o aumento da compreensão dos valores ambientais, além de uma atividade que surgiu devido à mudança fundamental no modo como a natureza é vista pela sociedade" (p. 12). Para os autores, o ecoturismo possui quatro elementos fundamentais: i) deslocamento para áreas naturais; ii) experiência do ambiente natural; iii) indução da conservação; e iv) educação e interpretação ambiental (WEARING; NEIL, 2001).

Para além da circunscrição como atividade econômica, defende-se uma percepção holística do ecoturismo, sustentada e coerente com seus fundamentos conceituais. Como forma de contribuir para a definição destes fundamentos, cumpre destacar como finalidade precípua do ecoturismo a superação da lógica de domínio da natureza e, para tanto, faz-se necessária "uma articulação ético-política entre as dimensões do meio ambiente, das relações sociais e da subjetividade humana, desenvolvida, via de regra, em espaços naturais, que aponta para uma nova ordem na relação ser humano/Natureza" (INÁCIO, 2003, p. 174).

Há uma contradição na aplicação do termo ecoturismo. A polissemia permite que seu uso se dê indistintamente no âmbito do trade turístico, podendo ser incorporado em práticas tradicionais do turismo de massa. Essa contradição, segundo o entendimento aqui defendido, está relacionada ao surgimento do setor ecoturístico como atividade econômica convencional sem reflexão sobre seu produto (NEIMAN; MENDONÇA, 2000). Logo, "[p]roduz viagens e não prioritariamente experiências, nem conhecimento. Só reproduz estratégias de marketing e conceitos administrativos convencionais, aplicados tradicionalmente a outras áreas do conhecimento humano." (NEIMAN; MENDONÇA, 2000, p.105). Zaú (2014), inclusive, promove clara distinção entre turismo de massa e ecoturismo ao referir-se às áreas naturais protegidas, nas quais "atividades relacionadas ao Turismo, seja ele de massa, seja ele Ecoturismo" deverão ser realizadas com base em evidências científicas e no princípio da precaução. 
O turismo de massa parece atuar com uma lógica incompatível com preocupações ambientais, como capacidade de suporte ou resiliência. A aplicação do conhecimento científico e tradicional opera no campo do ecoturismo. Ainda assim, apesar de "considerar o ecoturismo como uma possibilidade concreta tanto de proteção da natureza como de fortalecimento cultural das comunidades habitantes no destino do ecoturista", Layrargues (2004, p.1) atenta para dois riscos da atividade. Destaca que, devido à própria gênese de qualquer atividade atrelada à mercantilização da natureza, surge a possibilidade de "ultrapassar a capacidade suporte do ambiente e provocar a desestruturação cultural da comunidade local' (LAYRARGUES, 2004, p.3).

A minimização desses riscos está atrelada à elaboração de projetos de desenvolvimento do ecoturismo em consonância "com planos de manejo ambiental, que podem servir de base para a identificação de dimensões de realidade para o novo estilo de desenvolvimento sustentável transdisciplinar". (SONAGLIO; LAPOLLI, 2003, p. 166).

Inácio (2003, p.34), contudo, destaca, a partir de um amplo referencial teórico, "que o turismo, e menos ainda o ecoturismo, constitui a base de um processo de desenvolvimento territorial sustentável". O desafio ao ecoturismo é superar a primazia dos interesses econômicos na política de turismo, criticada por Vilani (2012a; 2012b) pelo estabelecimento de metas, nos Planos Nacionais de Turismo, que não possuem qualquer ação programática eficiente para a preservação e a valorização do patrimônio natural e cultural.

Diante da multiplicidade de conceitos e definições e das contradições apontadas, pode-se assinalar que o ecoturismo não é compatível com 0 turismo de massa, com a mercantilização da experiência da interação com a natureza e com a exploração das comunidades locais.

Pode se utilizar, em um esforço de síntese, a crítica de PortoGonçalves (2017) à exploração econômica da Amazônia para retratar a antinomia aqui defendida entre o ecoturismo e os padrões de mercantilização em massa de atrativos turísticos. O ecoturismo, nesse sentido, opera como um processo de superação da persistente "imagem colonial", na qual o Brasil é fonte de abundantes recursos naturais a serem explorados indefinidamente que, em última análise, sustenta a elaboração de "políticas que silenciam/invisibilizam" as populações indígenas e comunidades tradicionais, como quilombolas, ribeirinhos e seringueiros (PORTO-GONÇALVES, 2017, p.16). O "tempo do relógio abstrato do capital" (PORTO-GONÇALVES, 2017, p.37) viola os tempos da natureza e das comunidades afetadas pelos seus empreendimentos.

Com base na literatura pesquisada, para que o termo não seja submetido a rotulações e apropriações incompatíveis com sua natureza, utiliza-se ecoturismo como as práticas conduzidas a partir da: i) experiência em meio à natureza: realizada em áreas naturais protegidas ou não, nas quais pode haver presença de povos e comunidades tradicionais; ii) sustentabilidade: social, ecológica ambiental e cultural; iii) educação e interpretação ambiental; iv) conservação, recuperação e restauração ambiental; v) valorização, inclusão e respeito à comunidade receptora, às suas práticas, às manifestações e ao conhecimento sobre uso e manejo da 
biodiversidade (PIRES, 1998; WEARING; NEIL, 2001; FACO; NEIMAN, 2010).

A partir da revisão dos fundamentos teóricos, da gênese socioambiental e da aplicabilidade do termo, permite-se

[...] depreender que o ecoturismo surgiu como um meio de alcançar o desenvolvimento sustentável das regiões que ainda hoje apresentam importantes conjuntos naturais, de grande valor ecológico e paisagístico e como estratégia de conservação de culturas tradicionais. Portanto, ecoturismo não contém um fim em si, não existe para desenvolver-se a si mesmo, mas sim para possibilitar a inserção destas ditas regiões que, comumente, foram afastadas do desenvolvimento regional (NEIMAN; MENDONÇA, 2000, p. 105).

A conjunção dos cinco elementos centrais do ecoturismo, acima indicados, em favor do desenvolvimento regional demanda, por consequência, uma inversão no padrão secular de desenvolvimento brasileiro. As dimensões sociais e ambientais deverão ser priorizadas, contrariamente à constante hegemonia do imediatismo da dimensão econômica. Isso porque compreende-se que

Desenvolvimento não é um processo harmônico, mas ruptura de um quadro que se conformou historicamente. Portanto, alcançá-lo exige rupturas que causam, necessariamente, tensões e colocam em conflito diferentes projetos de uso e organização do território, o que em última instância significa a definição da própria forma de reprodução da vida. (MACEDO; PORTO, 2018, p. 622).

Daí a proposta de ecoturismo estar próxima, senão intimamente ligada, ao turismo comunitário, do qual podemos destacar como pressupostos 0 "protagonismo das populações locais no desenvolvimento do turismo, o fortalecimento da organização cultural, a distribuição equitativa dos benefícios socioeconômicos associados ao turismo" (BOTELHO; RODRIGUES, 2016, p.282).

$\mathrm{Na}$ literatura são encontrados estudos de caso que corroboram o (eco)turismo como movimento de resistência. Importa destacar, o turismo de base comunitária que tem se organizado e articulado, por exemplo, por meio da Rede de Turismo Comunitário da América Latina (REDTURS), criada em 2001. A REDTURS tem por objetivo "articular redes que vêm sendo construídas em diferentes escalas local e nacional, com a finalidade de diversificar as possibilidades de emprego e renda, de valorizar a cultura local e de fomentar o associativismo" (MORAES et al., 2017, p. 614).

Em seu sítio eletrônico, a REDTURS se apresenta como uma rede de comunidades campesinas e indígenas, instituições de apoio e profissionais que se volta para a auto-gestão do turismo, de modo que as comunidades 
assumam o protagonismo que Ihes corresponde no planejamento, na operação, na supervisão e no desenvolvimento dos seus negócios. O Ecuador oferece o maior número de destinos comunitários na REDTURS, um total de 52. Em seguida, os países com maior destaque são²: Brasil com 37 destinos; México, Nicarágua e Peru com 36 e; Costa Rica com 35.

Moraes et al. (2017, p. 614) acentuam que essa organização "vem influenciando outras práticas de turismo de base comunitária na região, tendo em vista os laços históricos e culturais dos países desde o México até o Polo Sul". Maldonado (2010 apud MORAES et al., 2017) indica que, em quase toda América Latina, é possível observar iniciativas de turismo comunitário em cerca de 300 destinos e 500 povos indígenas e comunidades rurais. Lustosa e Almeida (2011), destacam a resistência do povo Jenipapo-Kanindé, Aldeia Lagoa Encantada, Aquiraz, localizada no Ceará, que, por meio de um projeto de auto-gestão integrado à Rede Cearense de Turismo Comunitário (REDE TUCUM), resistiu à implantação de um empreendimento turístico internacional.

$\mathrm{Na}$ Costa Rica, redes associativas também favorecem o turismo comunitário e o protagonismo de comunidades rurais na gestão e na obtenção dos benefícios da atividade turística no país (ANDREU, 2008). A auto-gestão tem se mostrado uma alternativa dentro do modelo de ecoturismo praticado na Costa Rica, uma vez que as iniciativas de ecoturismo foram controladas por atores externos às comunidades locais e, por desdobramento, não foram alcançados os resultados de melhoria das condições de vida destas comunidades e de conservação (ANDREU, 2008).

O associativismo, a atuação em rede e a coesão das comunidades (LUSTOSA; ALMEIDA, 2011; NAVARRO; SANCHÉZ, 2012; BOTELHO; RODRIGUES, 2016) podem ser apontados como aspectos preponderantes para a consolidação de um movimento de ecoturismo contra-hegemônico com retorno e benefícios reais para as comunidades receptoras. No mesmo sentido, Müller (2004) discute o ecoturismo e o turismo cultural autogestionários em terras indígenas - povo Asuriní do Xingu - como alternativa econômica dentro das dinâmicas impostas pela globalização.

Neste contexto, pode-se, com base em Oliveira (2011), compreender o ecoturismo como um movimento de resistência à homogeneização e colonização dos territórios e à descontinuidade de práticas e manifestações socioculturais, ou, conforme tem-se reforçado, de valorização da diferença, da sociodiversidade brasileira, especialmente como protagonistas na gestão ecoturística, para além do papel de atrativos turísticos. Dessa forma, assim como o turismo comunitário, o ecoturismo, em sua essência, visa:

[...] se contrapor ao turismo massificado, requerendo menor densidade de infraestrutura e serviços e buscando valorizar uma vinculação situada nos ambientes naturais e na cultura de cada lugar. Não se trata, apenas, de percorrer rotas exóticas, diferenciadas daquelas do turismo de massa. Tratase de um outro modo de visita e hospitalidade, diferenciado em relação ao turismo massificado, ainda que porventura se 
dirija a um mesmo destino (BURSZTYN; BARTHOLO; DELAMARO, 2009, p. 86).

Em um cenário de expansão internacional do turismo, particulares de grandes redes hoteleiras, é compatível com a análise de Cruz (2009, p.106) afirmar que o ecoturismo pode contribuir para o desenvolvimento local como "uma forma de resistência ou mesmo uma contra-racionalidade à racionalidade hegemônica do capital".

Sob essa perspectiva o ecoturismo é analisado como uma alternativa de (ao) desenvolvimento que vai de encontro à tradicional dissociação entre natureza e sociedade, na qual a natureza é "convertida em uma simples variável a ser 'manejada', administrada e gerida, de modo a não impedir o "desenvolvimento" (ZHOURI et al., 2005, p. 15). Defende-se, portanto, que o ecoturismo é processo para a harmonização entre sociedade e natureza; é, em sua gênese, transformador e incompatível com a mercantilização da natureza e do patrimônio cultural. Por fim, deve ser estudado, estimulado e praticado como um fenômeno de ruptura e resistência, cuja essência é o respeito aos tempos e aos ciclos naturais e dos povos e comunidades tradicionais.

\section{Unidades de conservação e planejamento territorial}

Uma vez delimitada a aplicação de ecoturismo, nesta seção, serão realizados os apontamentos gerais sobre as unidades de conservação que, neste recorte, representam a base material de seu desenvolvimento e seu reconhecimento enquanto unidades territoriais de planejamento.

Para tanto, adota-se o marco legal para sustentar este argumento. A Constituição Federal (CF), em seu art. 225, $\S 1^{\circ}$, impõe ao Poder Público, como forma de assegurar o direito ao meio ambiente ecologicamente equilibrado, obrigações que têm a seguinte ordem de prioridade: i) "preservar e restaurar os processos ecológicos essenciais e prover o manejo ecológico das espécies e ecossistemas"; ii) "preservar a diversidade e a integridade do patrimônio genético do País [...]"; iii) "definir, em todas as unidades da Federação, espaços territoriais e seus componentes a serem especialmente protegidos [...]"; iv) "exigir, na forma da lei, para instalação de obra ou atividade potencialmente causadora de significativa degradação do meio ambiente, estudo prévio de impacto ambiental, a que se dará publicidade" (BRASIL, 1988).

Primeiramente, para a adequada interpretação destas obrigações, importa esclarecer que os incisos transcritos são um ponto de equilíbrio entre o antropocentrismo e o biocentrismo do texto constitucional (MACHADO, 2013). É forçoso destacar que os três primeiros incisos encerram ações biocêntricas. Logo, prioritariamente cabe ao Poder Público estabelecer um zoneamento que comporte a preservação e a restauração dos processos ecológicos, dos ecossistemas e da biodiversidade brasileira. Satisfeitas essas condições, assegurada a proteção de áreas naturais representativas e essenciais para o ambiente ecologicamente equilibrado, poderá o Poder Público permitir, por meio do devido procedimento de licenciamento 
ambiental, a instalação de empreendimentos causadores de significativo impacto ambiental.

Nesse sentido, a CF reforçou e detalhou a preocupação territorial trazida pela Política Nacional do Meio Ambiente (PNMA). A PNMA, instituída pela Lei 6.938/81, definiu, entre seus instrumentos, o zoneamento ambiental e a criação de espaços territoriais especialmente protegidos (art. 9o, II e VI). As diferentes categorias de unidades de conservação previstas no Sistema Nacional de Unidades de Conservação (Lei 9.985/2000) e aquelas específicas dos sistemas estaduais em vigor, as terras tradicionalmente ocupadas pelos índios (art. 231, da CF), as áreas de preservação permanente e as reservas legais (art. 3oㅡ. II e III, Lei 12.651/2012) são espécies fundamentais do gênero espaços territoriais. A partir da leitura do texto constitucional, podem ser identificados seis objetivos específicos dos espaços territoriais especialmente protegidos: i) preservar e assegurar os processos ecológicos essenciais (art. 225, § 1ํ, I); ii) preservar a diversidade e a integridade do patrimônio genético

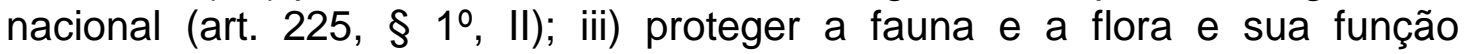
ecológica (art. 225, § 1ำ VII); iv) prevenir a extinção de espécies (art. 225, § 1ํ, VII); v) abrigar, defender e valorizar o patrimônio cultural brasileiro, como os sítios de valor histórico, paisagístico, artístico, arqueológico, paleontológico, ecológico e científico (art. 216, caput e V); e vi) proteger a organização social, os costumes, as línguas, crenças e tradições, e os direitos originários dos índios (art. 231).

Apesar do arcabouço jurídico em vigor, "o Brasil carece de uma política de turismo voltada às suas áreas protegidas, fazendo com que o tema sustentabilidade ocupe posição periférica na estratégia de turismo no país" (TCU, 2014, p.22). A importância de se relevar os aspectos normativos está atrelada ao fato de que a visitação às unidades de conservação e, portanto, 0 ecoturismo nessas áreas, está sujeita a um conjunto de normas ambientais. Por outro lado, o desenvolvimento do potencial ecoturístico em unidades de conservação está limitado pela inexistência desse tema na agenda pública. Logo, a legislação e as políticas ambiental e turística encontram-se nas unidades de conservação com esperados efeitos sinérgicos em favor da biodiversidade e do conhecimento tradicional associado, das práticas e costumes de comunidades tradicionais, da disponibilização de informações ambientais confiáveis, da promoção de políticas de turismo para o desenvolvimento de atividades de educação e interpretação ambiental, de recreação e de turismo ecológico em áreas protegidas e da recuperação/implantação de infraestrutura de apoio à pesquisa e à visitação em unidades de conservação no país (VALLEJO, 2009; BENSUSAN, 2006; TCU, 2014).

Portanto, justifica-se e releva-se uma abordagem interdisciplinar sobre o modelo de desenvolvimento adotado no Estado do Rio de Janeiro, particularizando a análise sobre os impactos da implantação de GPIs sobre as unidades de conservação e o ecoturismo. A temática, segundo Castro Júnior e colaboradores (2009), sempre esteve em segundo plano, fazendo-se, portanto, necessários esforços teórico-metodológicos para que 0 "planejamento e a gestão do território pelo Estado [sejam] capazes de promover desenvolvimento com distribuição de riquezas, associado à 
conservação ambiental" (p. 48). Isto é, apesar da ordem prioritária definida no texto constitucional, a atuação do Poder Público não tem sido direcionada para assegurar as preocupações biocêntricas contidas no art. 225 da CF.

O ponto de partida desta crítica está na investigação, sob a perspectiva da gestão integrada do território (BENSUSAN, 2006), dos processos e das dinâmicas que envolvem as escolhas pela criação e a não criação de unidades de conservação no Estado do Rio de Janeiro. Em analogia à previsão legal e ao debate teórico acerca das bacias hidrográficas, propõe-se a adoção das unidades de conservação como "instrumento de gestão ambiental e territorial" (COELHO et al., 2009, p. 77) dentro de um modelo de governança (multissetorial, multiatores, multiescalar e multidimensional) pautada na "responsabilidade política, na transparência e diversificação dos espaços de negociação e na ampliação dos atores para a definição da agenda pública, sustentadas nas prerrogativas governamentais de planejamento, elaboração e execução de políticas públicas" (MACHADO; VILANI, 2015, p.55).

Nessa perspectiva, o ecoturismo em áreas protegidas pode contribuir com o Sistema Nacional de Unidades de Conservação, particularmente com o objetivo de "promoção do desenvolvimento, em bases sustentáveis, nas unidades de conservação e respectivas áreas de influência" (BOTELHO; RODRIGUES, 2016, p.293).

Conforme destacado na Introdução, o incremento dos GPIs no Estado do Rio de Janeiro tem reproduzido o padrão de desenvolvimento primárioexportador, praticado na esfera federal. A situação é agravada pela elevada dependência do Estado do Rio de Janeiro para com a cadeia produtiva do petróleo, e essa especialização fez-se sentir na gravidade da crise econômica, devido à falta de investimentos em diversificação da economia estadual.

O planejamento territorial colocado em prática, segundo essa visão de desenvolvimento nacional e estadual, portanto, perpetua uma herança histórica de predação de recursos naturais, concentração de riquezas e distribuição social dos impactos negativos deste modelo. Consequemente, conflitos sociais e ambientais emergem cotidianamente no bojo das ações do Estado.

Esse processo se dá mesmo que a questão da conservação da natureza e sua compatibilidade com o crescimento econômico seja uma discussão de mais de quarenta anos. Apesar da longevidade dos debates internacionais e em âmbito nacional sobre o tema, os retrocessos ambientais na legislação e na política brasileira (VILANI, 2013), como no Código Florestal, no marco da mineração e da biodiversidade e no licenciamento ambiental, demonstram que essa conciliação ainda não é possível no Brasil. Contudo, tem ganhado relevo no País a discussão do ecoturismo como alternativa econômica aos GPIs, pelo potencial de geração de emprego e renda associado à proteção da biodiversidade e dos conhecimentos tradicionais. 
A relação entre turismo e conservação por meio de espaços territoriais protegidos pode ser remetida, na história recente, ao final da década de 1970 nos Estados Unidos, quando "a criação de áreas protegidas [tornou-se] uma solução bastante difundida no sentido de mitigar a degradação de habitats $e$ preservar espécies em várias partes do mundo" (MOULTON; SOUZA, 2006, p.158). Essa medida atende apenas parcialmente ao problema, visto que a deficiência de fiscalização e a falta de estratégias de manejo adequadas em países em desenvolvimento, como o Brasil, "representam obstáculos adicionais à conservação em reservas nas regiões que ainda concentram grande biodiversidade" (MOULTON; SOUZA, 2006, p.159).

Em interpretação da Lei 11.771, de 17 de setembro de 2008, que instituiu a Política Nacional de Turismo, Vilani (2012a) destaca nela a vinculação expressa aos princípios constitucionais da livre iniciativa, da descentralização, da regionalização e do desenvolvimento econômico-social justo e sustentável. Textualmente, "a Política Nacional de Turismo, em seus artigos $3^{\circ}$ e $4^{\circ}$, afirma $o$ necessário direcionamento do turismo para 0 desenvolvimento sustentável" (VILANI, 2012a, p.66). Para tanto, o planejamento do turismo é percurso inescapável. Beni (1999, p.11) define planejamento como

o processo de interferir e programar os fundamentos definidos do Turismo que, conceitualmente, abrange três pontos essenciais e distintos: estabelecimento de objetivos, definição de cursos de ação e determinação da realimentação, já que a atividade apresenta enorme interdependência e interação de seus componentes.

A atividade turística, se realizada de maneira sustentável, pode servir como instrumento para a mediação de conflitos que giram em torno das áreas protegidas. A participação política e a construção coletiva de planejamento de turismo sustentável em UCs proporcionam à população um sentimento de pertencimento e reconhecimento de seu valor e importância, estimulando a cidadania, criando laços entre população e natureza, possibilitando a conscientização da importância da conservação da biodiversidade e do patrimônio natural (MIKHAILOVA; MULBEIER, 2008).

Para tanto, o ecoturismo precisa ser tomado como política de Estado. A atuação da Administração Pública no planejamento e na gestão deve adotar por premissa a regulação e a orientação "das iniciativas públicas e privadas a serem implementadas de modo responsável para que propiciem um desenvolvimento harmonioso da economia e da sociedade com o mínimo de prejuízo ao ambiente e à cultura que o concebe" (LANZARINI; BARRETTO, 2014, p.195).

A reprodução do padrão primário-exportador, refletido nos GPIs do Estado do Rio de Janeiro, demanda uma revisão no planejamento público, o qual deve partir das unidades de conservação e das bacias hidrográficas como unidades de reordenamento territorial. No tocantes às unidades de conservação, a finalidade é evitar a fragmentação de ecossistemas frágeis e a 
extinção de espécies, reequilibrar e regulamentar a distribuição de processos produtivos, promover o ecoturismo como atividade de desenvolvimento socioeconômico, valorizar o conhecimento tradicional da biodiversidade e contribuir para a redução das desigualdades sociais e regionais. (CASAGRANDE; SOUZA, 2012; RÜCKERT, 2007; BECKER, 1991). Para tanto, as unidades de conservação devem ser analisadas segundo os critérios de diferenciação (presença de espécies endêmicas), de perigo (espécies ameaçadas de extinção) e de utilidade (potencial turístico verificável a partir das espécies, belezas cênicas e patrimônio presentes na área delimitada da unidade) por meio da análise de lacunas na conservação da biodiversidade no território do Estado do Rio Janeiro (VALLEJO, 2009).

Não se desconhecem aqui as críticas e os conflitos suscitados no bojo dos processos de criação destes espaços territoriais (SPINOLA, 2013; GUATURA et al., 1996), particularmente no Rio de Janeiro (IWAMA et al., 2014; GONÇALVES, 2011; KURY, 2009). Por outro lado, não se pode ignorar sua importância para a preservação da biodiversidade brasileira e seu potencial de valorização das comunidades tradicionais, desde que criadas em respeito aos princípios da participação e da publicidade, por exemplo. A presente reflexão parte da compreensão do ecoturismo fora da lógica de mercado, privilegiando o uso desta tipologia como aquela que encerra uma alternativa real ao turismo de massa, voltando-se à preservação do patrimônio natural e cultural (BARRETTO, 2003). Neste sentido,

\begin{abstract}
O ecoturismo pode ser uma alternativa de desenvolvimento econômico e sustentável, aliando geração de renda e empregos à preservação e conservação dos recursos e da qualidade do meio ambiente. $O$ que vem atraindo grande parcela de turistas do mundo todo é ver que os ecossistemas estão sendo cuidados, que existem lugares onde é possível vislumbrar biodiversidade com qualidade de vida e muitos amantes da natureza pagam para ver isso (MIKHAILOVA; MULBEIER, 2008, p.5).
\end{abstract}

Os grandes projetos nacionais de infraestrutura previstos simultaneamente no PAC, consoante o Plano Plurianual (PPA), e na Iniciativa de Integração Regional Sul-Americana (IIRSA) poderão influenciar 137 unidades de conservação, que somam cerca de 40 milhões de hectares, ou $41 \%$ da área total das unidades de conservação brasileiras. Além das unidades de conservação, 107 terras indígenas e 484 áreas prioritárias para a conservação da biodiversidade brasileira serão impactadas pelas obras. A Amazônia será o bioma mais atingido, 332 áreas prioritárias para conservação sob influência direta dos projetos (Quadro 2). (WANDERLEY et al., 2007).

As referidas áreas prioritárias para conservação dos biomas brasileiros estão previstas na Portaria 09/2007 do Ministério do Meio Ambiente (MMA). Esta versão da Portaria é uma atualização realizada segundo "metodologia [que] incorporou os princípios de planejamento sistemático para conservação 
e seus critérios básicos (representatividade, persistência e vulnerabilidade dos ambientes), priorizando o processo participativo de negociação $e$ formação de consenso" (BRASIL, 2007 - Prefácio).

Quadro 2: Impactos do PAC e IIRSA sobre biomas brasileiros.

Table 2: Impacts of PAC and IIRSA on Brazilian biomes.

\begin{tabular}{|l|c|c|c|}
\hline \multirow{2}{*}{ Bioma } & \multirow{2}{*}{$\begin{array}{c}\text { Áreas } \\
\text { prioritárias }\end{array}$} & \multicolumn{2}{|c|}{ Áreas prioritárias afetadas } \\
\cline { 3 - 4 } & 741 & 332 & $\%$ \\
\hline Amazônia & 420 & 62 & 44,8 \\
\hline Cerrado & 579 & 60 & 14,7 \\
\hline Mata Atlântica & 50 & 30 & 10,3 \\
\hline Pantanal & 74 & 9 & 60,0 \\
\hline Pampa & 238 & 0 & 12,1 \\
\hline Caatinga & 102 & 1 & - \\
\hline Marinho & & 0,9 \\
\hline
\end{tabular}

Fonte: Elaborado a partir de: Wanderley et al. (2007); Brasil (2007).

Source: Prepared from: Wanderley et al. (2007); Brasil (2007).

A partir da Quadro 2, é possível aferir uma clara dicotomia interna no planejamento das ações governamentais federais. Se, de um lado, são realizados esforços metodológicos para a definição de áreas prioritárias para conservação dos biomas brasileiros, por outro, são elaborados planos de obras alheios à política ambiental em curso. O uso de dados de 2007 é proposital e simbólico. Neste ano, foi iniciado o PAC e editada a Portaria 09 do MMA. Pode-se afirmar que 2007 é um marco no isolamento da questão ambiental, que passa a ser necessária tão somente como elemento formador de discursos oficiais para o público internacional.

Essa questão estende-se, também, às terras indígenas. Verdum (2012), a partir de dados da Fundação Nacional do Índio (FUNAl), destaca os impactos das grandes hidrelétricas e das obras do eixo de transporte previstas no PAC sobre povos indígenas, que já se encontravam em situação de risco. Diante da incapacidade do IBAMA em assegurar a proteção ambiental e se limitar a uma atuação meramente legitimadora de decisões previamente acordadas, o autor alerta que "as expectativas em relação ao futuro, na atual conjuntura de correlação de forças, não são e não podem ser de otimismo e esperança, e isso não é nada bom" (VERDUM, 2012, p.23).

A politização dos órgãos ambientais responsáveis pelas unidades de conservação, in casu, ICMBio, na esfera federal, e INEA, no Estado do Rio de Janeiro, a falta de investimentos no setor e a consequente precarização na prestação de serviços por esses órgãos são opções do Poder Público e, portanto, os principais obstáculos à efetivação das unidades de conservação como unidades territoriais de planejamento e, por desdobramento lógico, ao desenvolvimento do ecoturismo. 


\section{O ecoturismo pode superar o modelo desenvolvimentista no Estado do Rio de Janeiro?}

Em pesquisa realizada para determinar a sobreposição de obras do PAC, licenciadas pelo IBAMA, com unidades de conservação federais na Serra do Mar, Aguiar (2011) aplicou questionário junto a chefes das 55 unidades de conservação selecionadas, tendo a confirmação da sobreposição das obras em 29 respostas, ou seja, 52\% dos casos, com 3 respostas contrárias e 11 que desconheciam a sobreposição. Diante da análise e do estudo de caso propostos, a autora conclui que o PAC repete características das políticas de desenvolvimento da segunda metade do século XX como "busca de uma industrialização rápida, incentivo a grandes obras que vão na contramão das mais modernas diretrizes ambientais que buscam menor impacto ambiental, indicadores econômicos e grupo de decisão do programa concentrados na área econômica" (AGUIAR, 2011, p.88). As duas edições do PAC podem ser consideradas simbólicas para se compreender a falácia de um novo ciclo de desenvolvimento (SAMPAIO JR, 2012), particularmente por promover, na prática: "desindustrialização [...]; reprimarização das exportações; maior dependência tecnológica; maior desnacionalização; perda de competitividade internacional [...]; maior concentração de capital; crescente dominação financeira [...]" (GONÇALVES, 2012, p.638).

Adicionalmente, este modelo de aceleração do crescimento destrói a possibilidade de aproveitamento dos serviços ecossistêmicos oferecidos pelas unidades de conservação. Medeiros e Young (2011) destacam que serviços como extração de produtos florestais, preservação de estoques de carbono, uso público e conservação de fluxos hídricos possuem um potencial de arrecadação superior ao próprio custo de sua manutenção. Ilustram a situação com uma estimativa de arrecadação de $R \$ 459$ milhões pelo uso público em 18 parques nacionais, que ultrapassava, em 2008, o orçamento anual total ( $R \$ 316$ milhões) das 310 unidades de conservação federais (MEDEIROS; YOUNG, 2011).

É preciso lançar um novo olhar sobre as unidades de conservação, reconhecendo a importância econômica da visitação e da biodiversidade. $O$ ecoturismo pode ser o indutor de um modelo de desenvolvimento que se proponha a superar o principal obstáculo para a efetivação das políticas de conservação da natureza, qual seja a "articulação e a transversalidade necessárias entre os diferentes níveis governamentais e os diferentes setores e comunidades envolvidos a fim de que não sejam negligenciadas as demandas sociais, ambientais e econômicas de um país em permanente transformação" (PECCATIELLO, 2011, p.81). Este desafio tem um ator central, o "Estado como órgão planejador e gestor, que orienta os recursos financeiros e promove investimentos diretos no setor, concedendo incentivos fiscais e ordenando os territórios para o desenvolvimento da economia local, regional e nacional' (LANZARINI; BARRETTO, 2014, p.194-195).

No mesmo sentido, com base em Ansarah (2001) e Vilani (2012a), um modelo de desenvolvimento turístico que se proponha sustentável passa pela introdução nas políticas de turismo de ações para: 1) definir e implementar metas e objetivos mensuráveis de longo prazo; 2) desenvolver o ecoturismo 
em harmonia com as especificidades das áreas naturais e com a valorização dos povos e comunidades tradicionais e dos patrimônios culturais, históricos e paisagísticos; 3) fortalecer o desenvolvimento da atividade ecoturística, em parcerias com os atores sociais, comunidades locais e organizações populares, em regiões com menores índices de renda e emprego. Estes objetivos possuem relação direta com o ecoturismo em unidades de conservação, consoante o ora proposto, para integrar o desenvolvimento do Estado, particularmente das regiões turísticas no interior do Estado, procurando superar a questão das bases sociais da fragmentação, conforme terminologia de Vainer (2007).

Assim sendo, os GPIs implantados no Estado do Rio de Janeiro representam um modelo de desenvolvimento anacrônico, que não apenas ignora o potencial do turismo, de maneira geral, mas, particularmente, do ecoturismo. Destarte, a eficiência do ecoturismo no território do Estado do Rio de Janeiro demanda a superação da concentração de investimentos em GPIs e a "construção histórica, lenta e planejada de ações públicas responsáveis e orientadas por políticas consistentes" (LANZARINI; BARRETTO, 2014, p. 210).

A transversalidade e o efeito multiplicador do turismo poderão contribuir para a redução da fragmentação territorial, promovida pela expansão urbana e por GPIs no Estado do Rio de Janeiro, e o consequente "processo de extinção causado pela degradação dos habitats" que, em última análise, resulta em "paisagens dominadas pelo homem [que] tendem a reter uma amostra empobrecida e tendenciosa da diversidade original das biotas" (TABARELLI; GASCON, 2005, p. 186).

O fortalecimento deste debate, com a respectiva produção de evidências científicas e disseminação de experiências de ecoturismo, em especial o de natureza comunitária, pode induzir iniciativas de ecoturismo e contribuir para uma nova orientação das políticas estaduais. Defende-se a definição de bacias hidrográficas e unidades de conservação como unidades territoriais, como elementos agregadores para uma governança ambiental.

Cumpre reforçar que os GPIs no Rio de Janeiro refletem um modelo de desenvolvimento praticado e perpetuado no Brasil. $E$, apesar de todas os avanços normativos sobre o tema, Lino e Bechara (2002, p.59) destacam lacunas fundamentais na legislação ambiental brasileira que obstam à conservação da Mata Atlântica:

1. Dificuldade de aprovação de leis ambientais em virtude da força dos lobbies contrários, que, inclusive, têm contado, muitas vezes, com indiscutível e vergonhosa facilidade na edição de Medidas Provisórias contrárias ao meio ambiente;

2. Pequena representatividade do setor ambientalista no Congresso Nacional, Assembleias Legislativas Estaduais e Câmara dos Vereadores, de sorte que a leis infraconstitucionais não tendem a refletir a questão ambiental como de fato deveriam; 
3. A maior parte das leis ambientais tem uma postura reativa e proibitiva e não pró-ativa e estimuladora da conservação;

4. Superposição de leis nacionais, estaduais e municipais, decretos, resoluções etc., que acabam "confundindo" os aplicadores e os seguidores da norma abrindo enorme e indesejável espaço para infindáveis discussões acerca da regra prevalecente;

5. Existência de leis que, a despeito de regularem assuntos diversos, chocam-se com as leis ambientais ou interferem de modo prejudicial na política ambiental;

6. Descumprimento contumaz das leis em virtude de dois fatores básicos: falta de aceitação espontânea, pelos particulares e mesmo Poder Público, e debilidade ou mau uso dos instrumentos de coerção, pelo Estado.

A soma dos óbices jurídicos aos desafios político-institucionais retrata um diagnóstico pessimista para o Estado de Rio de Janeiro, que tende a acentuar os riscos à conservação da natureza e ao ecoturismo em seu território. As premissas sobre as quais assenta-se a proposta de ecoturismo ensejam uma ruptura com a racionalidade econômica e o padrão de fragmentação territorial. Por isso, para evitar a ingenuidade da proposta, se é preciso reconhecer a dificuldade de sua implementação, por outro lado, é necessário o engajamento cívico e científico para o avanço em propostas críticas e transformadoras.

É preciso, para tanto, reconhecer a magnitude dos desafios que envolvem uma ruptura com o padrão de desenvolvimento situado economicamente e influenciado pelo mercado internacional. Por outro lado, a exemplo da análise de Maldonado (2007) para comunidades rurais da América Latina, pode-se apontar como desafio e caminho para os povos indígenas e comunidades tradicionais implantarem iniciativas de ecoturismo no Brasil, em consonância com as experiências bem-sucedidas trazidas no início deste texto, a mobilização social e a afirmação identitária para sustentar a construção de:

[...] estruturas e meios de pressão política que Ihes permitam influenciar suas condições de vida e bem-estar de forma mais decisiva, fomentando as relações econômicas e institucionais de uma nova ordem. Somente aumentando o seu poder de barganha, as organizações comunitárias conseguirão, por um lado, promover políticas públicas que incentivem os seus projetos produtivos e, por outro lado, assinar acordos de comércio justo com operadores turísticos nacionais ou transnacionais (MALDONADO, 2007, p. 9).

O ecoturismo, diante das possibilidades descritas, pode fortalecer esse movimento de revisão nos padrões de desenvolvimento e na redução da dependência das rendas petrolíferas no Estado do Rio de Janeiro. 


\section{Considerações finais}

Ao levantar dados e informações sobre as unidades de conservação no Brasil e no Rio de Janeiro, demonstrou-se que estes espaços estão afastados da agenda prioritária do Administração Pública. Foi discutido que esse afastamento é resultado do padrão primário-exportador de desenvolvimento, pautado em grandes projetos de investimento. Esse padrão degradou e degrada todos os biomas brasileiros, fragmenta o território e acentua desigualdades sociais e regionais.

No Estado do Rio de Janeiro, em particular, devido à presença dos últimos remanescentes de Mata Atlântica, estudos sobre o ecoturismo têm o papel de contribuir para a consolidação de uma alternativa a este padrão de desenvolvimento. A produção de commodities, notadamente a especialização produtiva em petróleo e gás natural no Rio de Janeiro, está no centro da implementação de GPIs que têm operado como vetores da fragmentação territorial direcionada para e pelos interesses privados. A especulação imobiliária, a expansão urbana, os empreendimentos portuários, rodoviários e da cadeia petrolífera e petroquímica ditam o ritmo de controle territorial e, por consequência, de redução da área de Mata Atlântica no Estado do Rio de Janeiro.

A riqueza da sociobiodiversidade existente no Estado do Rio de Janeiro corrobora a proposta de utilização das unidades de conservação como unidades territoriais de planejamento e o ecoturismo como alternativa ao desenvolvimento e à especialização econômica no Estado. $O$ ecoturismo pode se consolidar, no Rio de Janeiro, como uma reação contra-hegemônica, que, neste contexto, representa um movimento de afastamento das práticas de privatização dos processos decisórios e do planejamento territorial para incluir povos e comunidades tradicionais como protagonistas em iniciativas autogestionárias.

O ecoturismo alternativo ao padrão de desenvolvimento em vigor, por seu turno, não pode ser conduzido por grandes atores do trade turístico. Os setores públicos e as populações residentes, em particular, devem ser os protagonistas nesta agenda de desenvolvimento. As evidências científicas devem trazer elementos teóricos e metodológicos e discutir experiências para fortalecer a busca por harmonização da sociedade com os tempos da natureza e dos povos e comunidades tradicionais.

Foram indicados, para isso, cinco elementos centrais ao ecoturismo com o intuito de enfatizar a gênese do termo. Assim, defende-se que 0 ecoturismo seja realizado em meio à natureza. A presença de povos e comunidades tradicionais não deve ser encarada como conflitante com 0 ecoturismo. Pelo contrário, a sociobiodiversidade brasileira deve ser valorizada e patrimonializada de forma holística e integrada. Por isso, a proposta de que 0 processo alcance as diferentes dimensões da sustentabilidade (social, ecológica ambiental e cultural). A literatura consultada, de forma consensual, ressalta a importância da educação e da interpretação ambiental no processo de aproximação do visitante aos valores socioambientais do local visitado. Dos instrumentos de conscientização, resultarão os dois aspectos finais do ecoturismo: a indução à conservação, à 
recuperação e à restauração ambiental e a valorização das culturas e dos saberes locais.

Esses foram os cincos alicerces apresentados para que se reflita sobre um fenômeno transformador, de ruptura e resistência, que pode ser representado pelo ecoturismo. Os desafios estão no nascedouro da proposta. Romper com padrões seculares e suas dinâmicas de poder e interesses não é trivial. Contudo, os esforços científicos devem caminhar de encontro aos processos que invisibilizam a degradação ambiental, a espoliação territorial e a segregação sociocultural.

Por fim, além de uma contribuição intedisciplinar que, a partir das Ciências Ambientais, alcança as Ciências Biológicas, Sociais e Jurídicas e ramos da Administração Pública e do Planejamento Regional, conforme indicado na introdução, a adoção de unidades de conservação como unidades territoriais de planejamento volta-se para um amplo debate acerca da mudança das premissas das políticas de desenvolvimento adotadas neste século XXI. Neste cenário, sustentou-se aqui um conjunto de argumentos favoráveis à consolidação do ecoturismo como a atividade central para se avançar em um modelo de desenvolvimento integrado, participativo e de longo prazo.

\section{Referências}

ADAMS, C. As roças e o manejo da mata atlântica pelos caiçaras: uma revisão. Interciencia, v. 25, n. 3, p. 143-150, 2000.

AGUIAR, C.D. Sobreposições entre políticas públicas: obras do PAC e unidades de conservação no corredor de biodiversidade da Serra do Mar. Brasília, 2011. 103f. Dissertação (Mestrado em Políticas Públicas e Desenvolvimento Sustentável) - Centro de Desenvolvimento Sustentável, Universidade de Brasília.

ANDREU, M. N. Organización y características del turismo rural comunitario en Costa Rica. Anales de Geografía, v. 28, n. 2, p. 167-188, 2008.

BARRETTO, M. Manual de iniciação ao estudo do turismo. Campinas: Papirus, 2003.

BECKER, B.K. Geografia Política e Gestão do Território no limiar do século XXI: uma representação a partir do Brasil. Revista Brasileira de Geografia, v. 53, n. 3, p. 169-182, 1991.

BENI, M. C. Política e estratégia do desenvolvimento regional: planejamento integrado e sustentável do Turismo. Turismo em Análise, v. 10, n. 1, p. 7-17, 1999.

BENSUSAN, N. Conservação da biodiversidade em áreas protegidas. Rio de Janeiro: FGV, 2006.

BORGES, R.; PEIXOTO, A.L. Conhecimento e uso de plantas em uma comunidade caiçara do litoral sul do Estado do Rio de Janeiro, Brasil. Acta Botanica Brasilica, v. 23, n. 3, p. 769-779, 2009. 
BOTELHO, E.S.; RODRIGUES, C. G. O. Inserção das iniciativas de base comunitária no desenvolvimento do turismo em parques nacionais. Caderno Virtual de Turismo, v. 16, n. 2, p. 280-295, 2016.

BRASIL. Ministério do Meio Ambiente. Unidades de Conservação por Bioma. Brasília: MMA, 26 fev. 2016. Disponível em: <www.mma.gov.br/cadastro.uc>. Acesso em: 12 abr. 2016.

BRASIL. Instituto Chico Mendes de Conservação da Biodiversidade. Sumário executivo do plano de ação nacional para a conservação da onça-pintada. Brasília, MMA; ICMBio, 2010.

BRASIL. Ministério do Meio Ambiente. Secretaria de Biodiversidade e Florestas. Áreas Prioritárias para Conservação, Uso Sustentável e Repartição de Benefícios da Biodiversidade Brasileira: Atualização - Portaria MMA n 9, de 23 de janeiro de 2007. Brasília: MMA, 2007.

BRASIL. Constituição da República Federativa do Brasil. DOU, 05 out. 1988. Disponível em <http://www.planalto.gov.br/ccivil 03/constituicao/constituição.htm>. Acesso em: 29 maio 2018.

BRITO, M.R.; SENNA-VALLE, L. Plantas medicinais utilizadas na comunidade caiçara da Praia do Sono, Paraty, Rio de Janeiro, Brasil. Acta Botanica Brasilica, v. 25, n. 2, p. 363-372, 2011.

BURSZTYN, I.; BARTHOLO, R.; DELAMARO, M. Turismo para quem? Sobre caminhos de desenvolvimento e alternativas para o turismo no Brasil. In: BARTHOLO, R.; SANSOLO, D.G.; BURSZTYN, I. Turismo de Base Comunitária: Diversidade de Olhares e Experiências Brasileiras. Rio de Janeiro: Letra e Imagem, 2009. p. 76-91.

CASAGRANDE, A.E.; SOUZA, E.B.C. O espaço e a demografia: o planejamento regional em perspectiva nas margens paranaenses do Lago de Itaipu. Sociedade e Território, v. 24, n. 1, p. 2-27, 2012.

COELHO, M.C.N.; CUNHA, L.H.; MONTEIRO, M.A. Unidades de conservação: populações, recursos e territórios. Abordagens da geografia e da ecologia política. In: GUERRA, A.J.T.; COELHO, M.C.N. (Orgs.). Unidades de conservação: abordagens e características geográficas. Rio de Janeiro: Bertrand Brasil, 2009. pp. 67-111.

COMISSÃO PRÓ-ÍNDIO DE SÃO PAULO (CPISP). Terras indígenas no Rio de Janeiro. Disponível em: <http://www.cpisp.org.br/indios/ html/uf.aspx?ID=RJ>. Acesso em: 07 ago. 2018.

CRUZ, R.C.A. Turismo, produção do espaço e desenvolvimento desigual: para pensar a realidade brasileira. In: BARTHOLO, R.; SANSOLO, D.G.; BURSZTYN, I. Turismo de Base Comunitária: Diversidade de Olhares e Experiências Brasileiras. Rio de Janeiro: Letra e Imagem, 2009. p. 92-107.

DIEGUES, A.C. A sócio-antropologia das comunidades de pescadores marítimos no Brasil. Etnográfica, v. 3, n. 2, p. 361-375, 1999.

DIEGUES, A.C. O mito moderno da natureza intocada. São Paulo: HUCITEC, 2008.

ENDRES, A.V. Sustentabilidade e ecoturismo: conflitos e soluções a caminho do desenvolvimento. Turismo em Análise, v. 9, n. 1, p. 37-50, 1998. 
FACO, R.A; NEIMAN, Z. A natureza do ecoturismo: conceitos e segmentação. In: NEIMAN, Z.; RABINOVICI, A. (Orgs.). Turismo e Meio Ambiente no Brasil. Barueri: Manole, 2010. pp. 43-63.

GONÇALVES, R. Novo desenvolvimentismo e liberalismo enraizado. Serviço Social \& Sociedade, n. 112, p. 637-671, 2012.

GUATURA, I.S.; COSTA, J.P.O.; CORREA, F.; AZEVEDO, P.U.E. A questão fundiária: Roteiro para solução dos problemas fundiários nas áreas protegidas da Mata Atlântica. Série: Conservação e Áreas Protegidas. Caderno 1, ed. 2. 1996.

INÁCIO, H.L.D. Ecodesenvolvimento e turismo: bases para uma outra relação com o planeta. Revista Eletrônica dos Pós-Graduandos em Sociologia Política da UFSC, v. 1, n. 1, p. 169-188, 2003.

IWAMA, A.Y.; LIMA, F.B.; PELLIN, A. Questão fundiária em áreas protegidas: uma experiência no Parque Estadual da Pedra Branca (PEPB), Rio de Janeiro, Brasil. Sociedade \& Natureza, v. 26, n. 1, p. 77-93, 2014.

KURY, K.A. Regularização Fundiária em Unidade de Conservação: O caso do Parque Estadual do Desengano/RJ. Boletim do Observatório Ambiental Alberto Ribeiro Lamego, v. 3, n. 2, p. 75-89, $2009 \mathrm{~b}$.

LANZARINI, R.; BARRETTO, M. Políticas públicas para um turismo responsável. Turismo - Visão e Ação, v. 16, p. 185-215, 2014.

LAYRARGUES, P.P. A função social do ecoturismo. Boletim Técnico do SENAC, v. 30, n. 1, p. 1-5, 2004.

LEITE, M.R.P. Relações entre a onça-pintada, onça-parda e moradores locais em três unidades de conservação da Floresta Atlântica do Estado do Paraná, Brasil. 84f. Dissertação (Mestrado em Ciências Florestais), Universidade Federal do Paraná, 2000.

LINO, C.F.; BECHARA, E. Estratégias e instrumentos para conservação, recuperação e desenvolvimento sustentável na Mata Atlântica. São Paulo: Conselho Nacional da Reserva da Biosfera da Mata Atlântica; Fundação SOS Mata Atlântica, 2002.

LUSTOSA, I. M. C.; ALMEIDA, M. G. Turismo em terras indígenas: auto-gestão e novo colonialismo no nordeste do Brasil. Revista Geográfica de América Central, v. 2, p. 1-15, 2011.

MACEDO, F.C.; PORTO, L. Existe uma Política Nacional de Desenvolvimento Regional no Brasil? Revista Brasileira de Gestão e Desenvolvimento Regional, v. 14, n. 2, p. 605-631, 2018.

MACHADO, C.J.S.; AVENA, R.C.S. A geração de passivos ambientais em bacias hidrográficas costeiras oriunda da abertura de novas rodovias: o caso da rodovia RJ-165 - Paraty-RJ/Cunha-SP. In: Anais do XV Simpósio Brasileiro de Recursos Hídricos. São Paulo: ABRH, p. 1-18, 2003.

MACHADO, C.J.S.; VILANI, R.M. Temas e problemas da vida em sociedade no Brasil. Rio de Janeiro: E-papers, 2016.

MACHADO, C.J.S. Governança climática no Antropoceno: da rudeza dos fatos à esperança no Brasil. Rio de Janeiro: E-papers, 2015. 
MACHADO, P.A.L. Direito ambiental brasileiro. São Paulo: Malheiros, 2013.

MALDONADO, C. Fortaleciendo redes de turismo comunitário. Revista @local.glob, $\quad$ n. $\quad 4, \quad$ p. 8-14, 2007. Disponível em: $<$ http://www.redturs.org/nuevaes/Maldonado-Artic-Rev-Turin\%20Esp.pdf $>$.

Acesso em: 07 ago. 2018.

MEDEIROS, R.; YOUNG, C. E. F. (Edits.). Contribuição das unidades de conservação brasileiras para a economia nacional. Brasília: UNEP-WCMC, 2011.

MIKHAILOVA, I.; MULBEIER, J. Ecoturismo em unidades de conservação: um estudo de caso do Parque Estadual do Turvo, Derrubadas - RS. Caderno Virtual de Turismo, v. 8, n. 3, 2008.

MORAES, E.A.; IRVING, M.A.; SANTOS, J.S.C.; SANTOS, H.Q.; PINTO, M.C. Redes de turismo de base comunitária: reflexões no contexto latino-americano. Revista Brasileira de Ecoturismo, v. 9, n. 6, p.612-623, 2017.

MOULTON, T.P.; SOUZA, M.L. Conservação com base em bacias hidrográficas. In: ROCHA, C.F.D.; BERGALLO, H.G.; SLUYS, M.V.; ALVES, A.S.A. (Edits.). Biologia da conservação: essências. São Carlos: RiMa, 2006. pp. 157-182.

MÜLLER, R.P. Duas décadas de projetos de desenvolvimento entre povos indígenas: da resistência às frentes de expansão do capitalismo nacional à globalização e ambientalismo dos anos 90. Revista de Estudos e Pesquisas, FUNAI, v.1, n.1, p.181-203, 2004.

NAVARRO, J.R.H.; SANCHÉZ, A.M. Promoción del Desarrollo Económico Local (DEL): experiencias desde el turismo rural comunitário. Tecnología en Marcha, v. 25, n. 46, p. 104-111, 2012.

NEIMAN, Z.; MENDONÇA, R. Ecoturismo: discurso, desejo e realidade. Turismo em Análise, v. 11, n. 2, p. 98-110, 2000.

OLIVEIRA, C.F. Ecoturismo como prática para o desenvolvimento socioambiental. Revista Brasileira de Ecoturismo, v. 4, n. 2, p.184-195, 2011.

PECCATIELLO, A.F.O. Políticas públicas ambientais no Brasil: da administração dos recursos naturais (1930) à criação do Sistema Nacional de Unidades de Conservação (2000). Desenvolvimento e Meio Ambiente, n. 24, p. 71-82, 2011.

PIRES, P.S. A dimensão conceitual do ecoturismo. Turismo - Visão e Ação, v. 1, n. 1, p. 75-91, 1998.

PIRES, P.S. O que é Ecoturismo? Em busca de uma resposta pela via da abordagem conceitual. Turismo - Visão e Ação, v. 2, n. 6, p. 119-128, 2000.

PORTO-GONÇALVES, C.W. Amazônia: encruzilhada civilizatória. Rio de Janeiro: Consequência, 2017.

RIO DE JANEIRO (Estado). Secretaria de Estado de Turismo. Anuário Estatístico de 2014. Rio de Janeiro: 2014. Disponível em: $<$ http://www.turisrio.ri.gov.br/observatorio.asp $>$. Acesso em: 30 jul. 2016.

RÜCKERT, A.A. A Política Nacional de Ordenamento Territorial, Brasil. Uma política territorial contemporânea em construção. Scripta Nova. Revista Electrónica de Geografía y Ciencias Sociales, v. XI, n. 245 (66), 2007. 
SAMPAIO JR., P. A. Desenvolvimentismo e neodesenvolvimentismo: tragédia e farsa. Serviço Social \& Sociedade, n.112, p. 672-688, 2012.

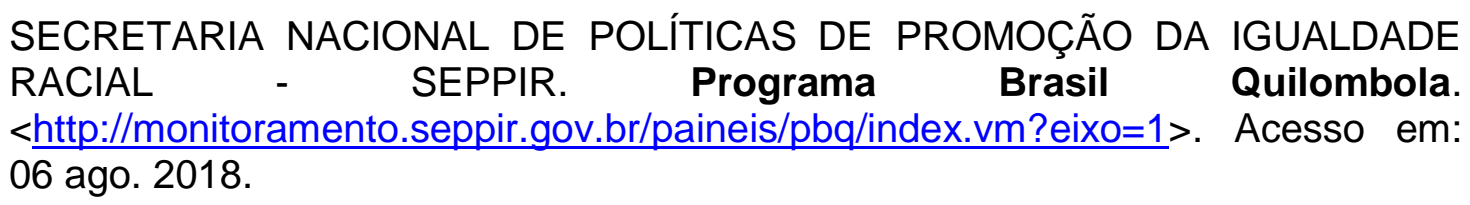

SONAGLIO, K.E.; LAPOLLI, E.M. Uma abordagem transdisciplinar para o desenvolvimento sustentável do ecoturismo. Turismo - Visão e Ação, v. 5, n. 2, p. 161-168, 2003.

SPINOLA, C.A. Parques nacionais, conservação da natureza e inserção social: uma realidade possível em quatro exemplos de cogestão. Turismo - Visão e Ação, v. 15, n. 1, p. 71-83, 2013.

TABARELLI, M.; GASCON, C. Lições da pesquisa sobre fragmentação: aperfeiçoando políticas e diretrizes de manejo para a conservação da biodiversidade. Megadiversidade, v. 1, n. 1, p. 181-188, 2005.

TRAJANO, E. Políticas de conservação e critérios ambientais: princípios, conceitos e protocolos. Estudos Avançados, v. 24, n. 68, p. 135-146, 2010.

TRIBUNAL DE CONTAS DA UNIÃO. Relatório de Auditoria. TC 006.762/20140. Brasília: TCU, 2014.

VAINER, C.B. Planejamento territorial e projeto nacional: os desafios da fragmentação. Revista Brasileira de Estudos Urbanos e Regionais, v. 9, n. 1, p. 9-23, 2007.

VALLEJO, L.R. Os parques e reservas como instrumentos de ordenamento territorial. In: ALMEIDA, F. G.; SOARES, L. A. A. (Orgs.). Ordenamento territorial. Rio de Janeiro: Bertrand Brasil, 2009. pp. 157-193.

VALLEJO, L.R. Conflitos territoriais nos Parques Estaduais do Desengano, da Serra da Tiririca e da llha Grande, RJ. In: SEMINÁRIO ÁREAS PROTEGIDAS E INCLUSÃO SOCIAL, 1, 2005, Rio de Janeiro. Anais eletrônicos.... Rio de Janeiro: IVT, 2005.

VERDUM, R. As obras de infraestrutura do PAC e os povos indígenas na Amazônia brasileira. Observatório de Investimentos na Amazônia, nota técnica n. 9, 2012.

VILANI, R.M. Legislação e política ambiental no Brasil: as possibilidades do desenvolvimento sustentável e os riscos do retrocesso ambiental. Revista Brasileira de Pós-Graduação, v. 10, n. 21, p. 829-860, 2013.

VILANI, R.M. Interpretação da Política Nacional de Turismo à luz do Princípio Constitucional de Desenvolvimento Sustentável. Cultur: Revista de Cultura e Turismo, v. 6, p. 60-72, 2012a.

VILANI, R.M. Aspectos constitucionais da atividade turística. Revista Direito Empresarial, v. 1, p. 229-245, 2012b.

WANDERLEY, I.F.; FONSECA, R.L.; PEREIRA, P.G.P.; PRADO, A.C.A.; RIBEIRO, A.P.; VIANA, E.M.; DUTRA, R.C.D.; OLIVEIRA, A.B.; BARBOSA, F.P.; PANCIERA, F. Implicações da Iniciativa de Integração da Infraestrutura Regional Sul-americana e projetos correlacionados na política de conservação no Brasil. Política ambiental, n. 3, p. 3-41, 2007. 
WEARING, S.; NEIL, J. Ecoturismo: impactos, potencialidades e possibilidades. São Paulo: Manole, 2001.

ZAÚ, A.S. A conservação de áreas naturais e o Ecoturismo. Revista Brasileira de Ecoturismo, v. 7, n. 2, p. 290-321, 2014.

ZHOURI, A.; LASCHEFSKI, K.; PEREIRA, D.B. Desenvolvimento, sustentabilidade e conflitos ambientais. In: ZHOURI, A.; LASCHEFSKI, K.; PEREIRA, D. B. (Orgs.). A insustentável leveza da política ambiental. Desenvolvimento e conflitos socioambientais. Belo Horizonte: Autêntica, 2005. pp. 11-24.

\section{Notas:}

1 Tais objetivos são: I - conservação in situ da biodiversidade; II - utilização sustentável de componentes da biodiversidade; III - repartição de benefícios derivados do acesso a recursos genéticos e ao conhecimento tradicional associado; IV - pesquisa e inventários sobre a biodiversidade; V - recuperação de áreas degradadas e de espécies sobre-exploradas ou ameaçadas de extinção; e VI valorização econômica da biodiversidade.

2 Informações retiradas da página inicial do sítio eletrônica da Red de Turismo Comunitario de America Latina. Disponível em: http://www.redturs.org. Acesso em: 07 ago. 2018 (tradução nossa).

\section{Agradecimentos}

Agradeço à Universidade Federal do Estado do Rio de Janeiro (UNIRIO) pelo financiamento da pesquisa, por meio do Edital Programa Pesquisador UNIRIO de Produtividade em Pesquisa - PROPG/DPQ 2017 (PQ-UNIRIO).

Rodrigo Machado Vilani: Universidade Federal do Estado do Rio de Janeiro, Rio de Janeiro, RJ, Brasil.

E-mail: rodrigo.vilani@unirio.br

Link para o currículo Lattes: http://lattes.cnpq.br/9026743148214335

Data de submissão: 06 de junho de 2018

Data de recebimento de correções: 06 de agosto de 2018

Data do aceite: 06 de agosto de 2018

Avaliado anonimamente 